Revista Ibero-Americana de Ciências Ambientais Ibero-American Journal of Environmental Science

\title{
Avaliação dos efeitos de biossurfactantes produzidos por Bacillus subtilis LBBMA 4914 e Pseudomonas aeruginosa LBBMA $4951 E$ e surfactantes sintéticos sobre larvas de Culex quinquefaciatus
}

Mosquitos da família Culicidae estão presentes em todo o território nacional podendo agir como vetores de doenças diversas, a exemplo da filariose transmitida por Culex quinquefasciatus. A evidência de resistência aos inseticidas tradicionais tem estimulado o desenvolvimento de pesquisas com novos compostos com potencial ação larvicida. No presente trabalho foram avaliados os efeitos de agentes tensoativos biológicos, os biosurfactantes ramnolipideos produzidos por Pseudomonas aeruginosa LBBMA 4951e lipopetídeos produzidos por Bacillus subtilis LBBMA 4914, além dos sintéticos SDS - Dodecil Sulfato de Sódio, Twen 80 e Triton X, sobre larvas de 3 e 4 instar de C. quinquefasciatus. Os resultados obtidos mostraram-se bastantes promissores indicando grande potencial de ação bioinseticida por parte dos biossurfactantes avaliados, destacando-se a surfactina com ação larvicida sobre $75 \%$ do total de espécimes de $C$. quinquefascitus expostos àquele tensoativo por $96 \mathrm{~h}$. Em relação aos surfactantes sintéticos, observou-se resultado mais pronunciado para Triton $\mathrm{X} 100$, seguido de Tween 80

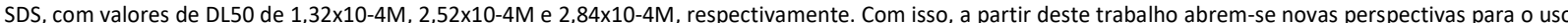
daqueles tensoativos no controle da proliferação de C. quinquefascitus assim como novos testes para a avaliação de seu efeito sobre outras espécies de Culicidae.

Palavras-chave: Culex; Bioinseticida; Surfactina; Ramnolipídeos.

\section{Assessment of the biosurfactant effects produced BY Bacillus subtilis LBBMA 4914 and Pseudomonas aeruginosa LBBMA $4951 E$ and sintetic surfactants about Culex quinquefasciatus larvaes}

\begin{abstract}
Family Culicidae mosquitoes are present throughout the national territory can act as vectors of several diseases, such as filariasis transmitted by Culex quinquefasciatus. Evidence of resistance to traditional insecticides has stimulated the development of research on new compounds with potential larvicidal action. The present study evaluated the effects of the biosurfactants ramnolipideos produced by Pseudomonas aeruginosa LBBMA 4951and lipopetides produced by Bacillus subtilis LBBMA 4914 besides synthetic surfactant SDS - Sodium Dodecyl Sulfate, Twen 80 and Triton X on larvae C. quinquefasciatus instar 3 and 4 . The results proved very promising indicating great potential for bioinsecticide action on the part of the evaluated biosurfactants highlighting the surfactin action with larvicide over $75 \%$ of $C$. quinquefascitus specimens exposed to that surfactant for 96 hours. Regarding synthetic surfactants there was more pronounced results

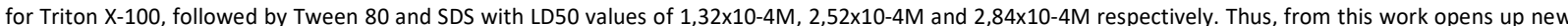
prospects for the use of those surfactants to control C. quinquefascitus proliferation as well as new tests to evaluate its effect on other species of Culicidae.

Keywords: Culex; Bioinseticide; Surfactin; Rhaminolipids.
\end{abstract}

Topic: Epidemiologia e Saúde Ambiental

Reviewed anonymously in the process of blind peer.

Adriano Guimaraes Parreira

Universidade Federal de Viçosa, Brasil

http://lattes.cnpq.br/1803178442452988

aguiparreira@ufsj.edu.br

Stenio Nunes Alves

Universidade Federal de Minas Gerais, Brasil

http://lattes.cnpq.br/8281387424304808

stenioalves@ufsj.edu.br

Marcos Rogerio Totola

Universidade Federal de Viçosa, Brasil

http://lattes.cnpq.br/4086846335875092

totola@ufv.br

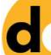

DOI: 10.6008/SPC2179-6858.2016.002.0008
Received: 05/01/2016

Approved: 10/04/2016
Referencing this:

PARREIRA, A. G.; ALVES, S. N.; TOTOLA, M. R.. Avaliação dos efeitos de biossurfactantes produzidos por Bacillus subtilis LBBMA $4914 \mathrm{e}$ Pseudomonas aeruginosa LBBMA 4951E e surfactantes sintéticos sobre larvas de Culex quinquefaciatus. Revista Ibero-Americana de Ciências Ambientais, v.7, n.2, p.101-110, 2016. DOI: http://doi.org/10.6008/SPC2179-6858.2016.002.0008 


\section{INTRODUÇÃO}

O combate à proliferação de mosquitos vetores de doenças, a exemplo de $C$. quinquefasciatu transmissor da filariose, representa sério desafio aos sistemas públicos de saúde, gerando esforços dispendiosos tanto nas frentes de prevenção quanto na remediação dos problemas advindos de sua infestação. A espécie $C$. quinquefasciatus é de grande importância em Saúde Pública por estar relacionada ao transmissor da filariose na América Latina, estando amplamente distribuída em todo o território nacional e intimamente associada a presença humana, sobretudo por se constituir de indivíduos hematófagos (JIANG et al., 2009). Já existem relatos na literatura indicando resistência a inseticidas em populações de $C$. quinquefasciatus, assim como em populações de Aedes aegypti e Anopheles sp (YANOLA et al., 2015).

Atualmente, tem-se intensificado a pesquisa com novos compostos potencialmente larvicidas, a exemplo de extratos de plantas, óleos vegetais e substâncias obtidas de microrganismos, especialmente fungos e bactérias, destinados ao controle da proliferação de mosquitos das mais diversas espécies (ELUMALAl et al., 2013; BAWIN et al, 2016). Particularmente, agentes com atividade interfacial, os chamados surfactantes, podem representar alternativas interessantes aos compostos larvicidas tradicionalmente utilizados, sobretudo por sua efetividade em pequenas doses e diferentes mecanismos de ação, como a desintegração de lipídeos de membrana (CAMEOTRA et al., 2004). Surfactantes de origem biológica, ou biossurfactantes, especialmente os produzidos por bactérias, têm sido relatados como importantes agentes larvicidas, apresentando ainda vantagens adicionais por serem compostos de origem biológica, mais efetivos que os sintéticos, atóxicos e até então pouco explorados para aquela finalidade (DAS et al., 2013).

Com base nas considerações apresentadas, e impactos recentemente observados no Brasil no que tange a disseminação de mosquitos vetores de doenças, o presente trabalho buscou avaliar o efeito de tensoativos sobre larvas, pupas e insetos adultos de $C$. Quinquefasciatus. Foram testados, sob diferentes concentrações, dois surfactantes de origem biológica, surfactina e ramnolipídeos, obtidos a partir do cultivo de Bacillus subtilis e Pseudomonas aeruginosa, respectivamente, e os surfactantes sintéticos SDS (Dodecil Sulfato de Sódio), Triton X e Tween 80. Partindo-se dos dados levantados espera-se que novas estratégias de controle da proliferação dos mosquitos transmissores da filariose possam ser implementadas, assim como novos estudos de avaliação dos efeitos dos melhores tensoativos obtidos neste trabalho sobre outros espécimes da família Culicidae sejam vislumbrados e iniciados.

\section{REVISÃO TEÓRICA}

Mosquitos hematófagos representam um motivo de preocupação em todo o mundo, sobretudo nas regiões tropicais pela possibilidade de transmitirem doenças ao homem e aos animais ou, simplesmente, pelo fato de gerarem incômodos ou desconfortos que refletem em prejuízos econômicos e na qualidade de vida da população. C. quinquefasciatus representa um desses exemplos, um mosquito tipicamente urbano e doméstico que pode transmitir a filariose. Sua distribuição geográfica estende-se por todas as regiões tropicais sendo fortemente dependente da presença humana, devendo-se ressaltar que suas larvas se 
desenvolvem preferencialmente em água proveniente de esgoto doméstico (ANDRADE et al., 2010). As fêmeas adultas daquela espécie possuem tendência à alimentação de sangue proveniente do homem (CONSOLI et al., 1994), o que estimula seu desenvolvimento em regiões urbanizadas. Além de provocarem incômodos às comunidades próximas a seus criadouros (TAIPE-LAGOS et al., 2003), o mosquito $C$. quinquefasciatus é vetor de vários agentes patogênicos (FORATTINI, 2002), o que justifica sua importância em Saúde Pública e a necessidade de seu controle em áreas de infestação. C. quinquefasciatus Say é um mosquito cosmopolita, domiciliado e era responsável por transmitir o nematóide da filariose, Wuchereria bancrofti, em regiões do Brasil como Manaus, Belém, Recife, Maceió e Salvador, dentre outras localidades do país (DEANE, 1951). Nos últimos anos, apenas a região metropolitana de Recife (PE) passou a ser considerada uma área endêmica (MEDEIROS et al., 2003). Atualmente, a filariose linfática expõe 1,2 bilhões de pessoas em 58 países ao risco de contraírem a doença, sendo que 120 milhões de pessoas se encontram infectadas e 40 milhões dessas desfiguradas e incapacitadas para o trabalho (WHO, 2015).

O papel dos insetos e de outros invertebrados como transmissores de agentes causadores de doenças foi comprovado cientificamente no final do século XIX. A descoberta foi feita pelo médico escocês Patrick Manson em 1877 (reportada em 1878), que constatou que os vermes causadores da filariose (W. bancrofti) se desenvolviam no interior de mosquitos (C. pipiens quinquefasciatus). Deste momento em diante, o papel de outros invertebrados como transmissores de doenças foi amplamente comprovado, como a malária transmitida por mosquitos do gênero Anopheles (1887), a febre do gado "texana" transmitida por carrapatos (1893), a "nagana" transmitida por moscas Tse-tse (1895), a peste bubônica transmitida por pulgas de ratos (1898), a febre amarela transmitida por mosquitos (1901), a doença de Chagas transmitida por triatomídeos (1909), além da dengue transmitida pelo mosquito Aedes aegypti, presente em mais de 100 países e cuja distribuição tem aumentado nas últimas décadas. O gênero Culex, criado por Linnaeus em 1758 e cujos representantes foram vulgarmente chamados de mosquitos, apresenta a maior variedade de espécies entre os culicídeos, abrangendo uma grande variedade de nichos, dos criadouros naturais como bromélias, aos artificiais, como pneus e vasos de plantas (LAPORTA et al., 2006). Existem mais de 300 espécies de Culex descritas, das quais algumas representam capacidade vetora e, portanto, tem interesse médico. Entre eles, encontra-se o $C$. quinquefasciatus, que representa um grande desafio para a saúde pública devido a sua grande dispersão por países de clima tropical e capacidade vetora para arborivores e filarioses, apesar do fator endêmico estar restrito a uma região no Brasil, conforme relatado (TAIPE-LAGOS et al., 2003).

C. quinquefasciatus desenvolve-se por meio de ciclo completo implicando em quatro etapas que contemplam formas distintas. As fases de ovo, larva e pupa vivem na água, geralmente estagnada, enquanto na fase adulta exploram os ambientes terrestres e aéreos. Uma única oviposição de Culex pode resultar em mais de 200 ovos. Esses resultarão em número semelhante de larvas de primeiro estágio e o desenvolvimento desses indivíduos até quarto estágio e posterior pupação dependerá da pressão exercida por vários fatores sobre a população de larvas (BARATA et al., 2007). No que se refere ao controle de sua proliferação, a maioria das tentativas de controle dos mosquitos não tem surtido os efeitos desejados devido, sobretudo a grande capacidade de reprodução e flexibilidade genômica dos mosquitos, associado ao fato da 
resistência crescente aos inseticidas tradicionais, o que tem levado ao ressurgimento de parasitoses e viroses transmitidas por mosquitos diversos (WILKE, 2008).

Surfactantes de origem biológica, ou biossurfactantes, assim como surfactantes sintéticos, são moléculas anfipáticas constituídas por uma porção hidrofóbica e uma porção hidrofílica o que permite, por isso, sua distribuição em interfaces com diferentes graus de polaridade. Os biossurfactantes apresentam algumas vantagens frente aos surfactantes sintéticos já que suas moléculas apresentam baixa toxicidade, alta capacidade emulsificante e, sendo de origem microbiana, são também biodegradáveis (NITSCHKE et al., 2002). Conforme observou Marcos Gugliotti (2010), agentes tensoativos apresentam acentuada ação mosquitocida, haja vista que os mosquitos afundam e morrem no momento da oviposição nos sistemas aquosos, dada a redução da tensão superficial da água na presença daqueles agentes. Váios relatos na literatura apontam para o sucesso no uso de surfactantes produzidos por isolados de Bacillus sp no que se refere ao controle da infestação de mosquitos do genero Culex e Aedes, principalmente. Gheetha et al. (2011) observaram importante atividade larvicida e pupacida em C. quinquefasciatus e A. aegypti provocada por surfactina produzida por isolados de Bacillus subtilis (VCRC B471). No Brasil não há relatos dos efeitos de surfactantes de origem biológica produzidos por isolados de B. Subtilis e P. aeruginosa sobre larvas de $C$. quinquefasciatus.

\section{METODOLOGIA}

Os experimentos foram conduzidos no LBBMA-UFV (Laboratório de Biotecnologia e Biodiversidade para o Meio Ambiente da Universidade Federal de Viçosa, Viçosa, MG) e no Insetário da UFSJ-CCO (Universidade Federal de São João Del Rei - Campus Centro Oeste Dona Lindu, Divinópolis, MG).

\section{Isolados produtores de biossurfactantes e condições de cultivo}

Os microrganismos produtores de biossurfactantes empregados nos experimentos de cultivo foram cepas de Bacillus subtilis ATCC 19659 e Pseudomonas aeruginosa ATCC 25619, pertencentes à coleção de culturas do LBBMA-UFV. Os isolados foram avaliados quanto à capacidade de produção de biossurfactantes em aerobiose, inoculados em frascos Erlenmeyer, contendo os meios minerais M1, M2 modificado e M3 (Tabela 1), com glicose como fontes de carbono a 2,0 \% (p/v) e incubados em shaker a 30ㄷ e a $150 \mathrm{rpm}$ por $72 \mathrm{~h}$.

Tabela 1: Composição dos meios minerais $\mathrm{M} 1, \mathrm{M} 2$ modificado e $\mathrm{M} 3$ ( $^{-1} \mathrm{~L}^{-1)}$ empregados no cultivo dos isolados de $B$. subtilis LBBMA 4914 e $P$. aeruginosa LBBMA 4951 durante a triagem de produtores de surfactantes.

\begin{tabular}{lccc}
\hline & \multicolumn{3}{c}{ CONCENTRAÇÃO (g L $\mathbf{~}^{-1}$ ) } \\
\cline { 2 - 4 } COMPONENTE & $\mathbf{M 1}$ & $\mathbf{M} 2$ & $\mathbf{M}$ \\
\hline $\mathrm{Na}_{2} \mathrm{HPO}_{4}$ & - & 2,7 & 2,7 \\
$\mathrm{KH}_{2} \mathrm{PO}_{4}$ & $\mathbf{0 , 5}$ & 1,4 & 1,4 \\
$\mathrm{~K}_{2} \mathrm{HPO}_{4}$ & $\mathbf{1 , 0}$ & - & - \\
$\left(\mathrm{NH}_{4}\right)_{2} \mathrm{SO}_{4}$ & 0,5 & 0,5 & 0,5 \\
$\mathrm{NaNO}_{3}$ & 1,0 & - & 1,0 \\
$\mathrm{MgSO}_{4} \cdot 7 \mathrm{H}_{2} \mathrm{O}$ & 0,154 & 0,154 & 0,154 \\
$\mathrm{~K}_{2} \mathrm{SO}_{4}$ & 0,36 & 0,36 & 0,36 \\
$\mathrm{CaCl}_{2} \cdot 2 \mathrm{H}_{2} \mathrm{O}$ & 0,01 & 0,01 & 0,01
\end{tabular}




\begin{tabular}{llll}
$\mathrm{FeSO}_{4} \cdot 7 \mathrm{H}_{2} \mathrm{O}$ & 0,027 & 0,027 & $\mathbf{0 , 0 0 7}$ \\
$\mathrm{NaCl}$ & 0,1 & 0,1 & 0,1 \\
Extrato de levedura & 0,01 & 0,01 & 0,01 \\
\hline * Solução de micronutrientes & $1,0 \mathrm{~mL}$ & $1,0 \mathrm{~mL}$ & $1,0 \mathrm{~mL}$ \\
$\mathbf{p H}$ & $\mathbf{6 , 8}$ & $\mathbf{6 , 8}$ & $\mathbf{6 , 8}$ \\
\hline
\end{tabular}

Fonte: Lima (2003).

\begin{tabular}{ll}
\hline *Solução de Micronutrientes & $\mathbf{g ~ L}^{-1}$ \\
\hline $\mathrm{MnSO}_{4} \cdot 4 \mathrm{H}_{2} \mathrm{O}$ & 0,02 \\
$\mathrm{ZnSO}_{4} \cdot 7 \mathrm{H}_{2} \mathrm{O}$ & 0,525 \\
$\mathrm{CuSO}_{4} \cdot 7 \mathrm{H}_{2} \mathrm{O}$ & 0,705 \\
$\mathrm{CoCl}_{2} \cdot 6 \mathrm{H}_{2} \mathrm{O}$ & 0,2 \\
$\mathrm{H}_{3} \mathrm{BO}_{3}$ & 0,02 \\
$\mathrm{Na}_{2} \mathrm{MoO}_{4} \cdot 2 \mathrm{H}_{2} \mathrm{O}$ & 0,015 \\
\hline
\end{tabular}

Fonte: Banat et al. (1991).

\section{Avaliação da produção de biossurfactantes}

Transcorrido o período de incubação mencionado acima, o volume contido nos frascos Erlenmeyer foi centrifugado a $7000 \mathrm{~g}$ (FANEM ${ }^{\circ}$ - Modelo 206 bl) por 10 minutos à temperatura ambiente para a remoção das células em suspensão. O sobrenadante das culturas foi coletado e submetido ao teste qualitativo do colapso da gota (BODOUR et al., 1998). O teste qualitativo do colapso da gota foi realizado em tampas de microplacas em polipropileno contendo 96 poços rasos. Os poços das tampas foram untados com $2 \mu \mathrm{L}$ de óleo de motor 10W-40 e deixados em repouso por $24 \mathrm{~h}$. Em seguida, foram dispensados $5 \mu \mathrm{L}$ da amostra a ser testada em cada um dos poços, em triplicata, e o espalhamento das gotas avaliado um minuto depois. $\mathrm{O}$ resultado foi considerado positivo para os casos em que o diâmetro da gota apresentou-se maior que o de uma gota de água deionizada, utilizada como controle negativo.

\section{Extração e pré-purificação dos biossurfactantes}

A produção dos surfactantes microbianos foi executada nas condições e com os isolados bacterianos selecionados na etapa anterior. Frascos Erlenmeyer de $500 \mathrm{~mL}$ foram preenchidos com $250 \mathrm{~mL}$ do meio de cultura selecionado, inoculados com as cepas escolhidas e incubados sob as melhores condições de cultivo. Transcorrido o período de incubação, o volume neles contido foi centrifugado a $7000 \mathrm{~g}$ (Fanem - Modelo $206 \mathrm{bl)}$ por 10 minutos à temperatura ambiente e o sobrenadante utilizado na próxima etapa de prépurificação dos biossurfactantes produzidos. A extração e pré-purificação foram executadas empregando-se o processo de extração ácida. Para tanto, as moléculas de biossurfactantes dispersas no sobrenadante do centrifugado foram precipitadas a partir do ajuste do $\mathrm{pH}$ da solução para 2,0, empregando-se para isso solução $\mathrm{HCl}$ 6,0 M. Os frascos permaneceram incubados overnight em geladeira a $4^{\circ} \mathrm{C}$ e a partir de então os extratos encontravam-se prontos para uso (Youssef et al., 2007).

\section{Liofilização do extrato semi-purificado de biossurfactantes}


Todo o conteúdo precipitado após a etapa anterior foi transferido para potes coletores em polipropileno, preenchidos com aproximadamente 1/3 de seu volume total. Em seguida, foram vedados com filme plástico perfurados em suas superfícies superiores e então congelados a - $8 \stackrel{\circ}{ } \mathrm{C}$ antes da liofilização. Após o congelamento foram colocados em liofilizador (Liobras ${ }^{\circledR}$ modelo Liotop L101) por um período de 48 horas. Foram preparadas soluções dos biossurfactantes surfactina e raminolipídeos a $1,0 \mathrm{mg} \mathrm{mL}^{-1}$ a partir do pó semi-purificado obtido.

\section{Montagem dos sistemas aquosos}

As etapas de avaliação dos efeitos dos surfactantes sobre o número de larvas, pupas ou insetos adultos vivos ao longo do tempo e montagem dos sistemas aquosos, constituídos por copos plásticos protegidos por filme de PVC e preenchidos com $100 \mathrm{~mL}$ de água destilada e ração, foram conduzidas no insetário da UFSJ-CCO. Foram adicionados $100 \mathrm{~mL}$ das soluções aquosas dos surfactantes sintéticos SDS, Tween e Triton X a 0,001M, 0,0001M e 0,00001 M e um total de 20 larvas em cada copo, coletadas no meio ambiente por meio de armadilhas montadas no Campus da UFSJ-CCO contendo atrativos para $C$. quinquefasciatus. De maneira similar, foram preparados os microcosmos contendo os biossurfactantes produzidos pelos microrganismos avaliados, ou seja, surfactina e ramnolipídeos, a 1,0 $\mathrm{mg} \mathrm{mL}^{-1}$. Os sistemas foram monitorados em intervalos de 24 horas até a transformação de todas as larvas em adultos, sendo observado o número total de larvas, pupas ou insetos adultos vivos ou mortos em cada microcosmo. Os experimentos foram montados com três repetições além de um grupo controle para cada tratamento sem a adição dos compostos tensoativos. A análise da ação dos surfactantes biológicos baseou-se no efeito dos mesmos sobre as larvas de $C$. quinquefasciatus contidas nos copos contendo surfactina ou ramnolipídeos a $1,0 \mathrm{mg} \mathrm{mL}^{-1}$. A fim de se verificar a suscetibilidade das larvas aos surfactantes sintéticos, utilizou-se análise estatística através do teste de Probit empregando-se o Programa DL 50 .

\section{RESULTADOS E DISCUSSÃO}

Em relação aos efeitos dos surfactantes sintéticos pudemos observar que, no caso do Tween $80^{\circ}$, ao final de $24 \mathrm{~h}$ de exposição havia, em média, um total de 15 pupas mortas sendo que, ao final de $48 \mathrm{~h}$ já não se via mais pupas vivas na maior concentração testada, comprovando-se com isso potencial efeito pupacida daquele composto sobre aqueles espécimes de Culicidae. Para o mesmo composto a 0,0001M, por sua vez, observou-se que após $120 \mathrm{~h}$ de exposição já não eram encontradas quaisquer larvas ou pupas vivas. Em ambos os casos não foram observados adultos vivos.

Ao final de $144 \mathrm{~h}$ de exposição ao tensoativo e a 0,00001M foi observada uma média de 10 adultos vivos, indicando ação larvicida daquele agente sobre 50\% do total de espécimes inicialmente incubados. Os resultados obtidos para Tween 80 indicam um efeito dose-dependente, sendo encontrado um valor de $\mathrm{DL}_{50}$ de $2,52 \times 10^{-4} \mathrm{M}$.

Para o ensaio empregando-se o surfactante sintético Triton $X^{\circ} 100$, observou-se que o efeito do mesmo foi bastante pronunciado sobre as larvas em todas as concentrações testadas $(0,001 \mathrm{M}, 0,0001 \mathrm{M}$ e 
0,00001M), haja vista que ao final de $48 \mathrm{~h}$ de exposição, todas as larvas encontravam-se mortas. Com isso, o surfactante Triton $X^{\bullet} 100$ mostrou-se o mais eficiente em termos de eliminação dos indivíduos no menor tempo possível, dentre todos os agentes tensoativos avaliados. Foi encontrado um valor de $\mathrm{DL}_{50}$ de $1,32 \times 10^{-}$ ${ }^{4} \mathrm{M}$, o menor valor em comparação com os demais. Seu efeito pronunciado também é relatado por Gugliotti em 2011, que também observou importante efeito mosquitocida de Triton X 100 sobre várias espécies dos gêneros Anopheles, Culex ou Aedes.

Para o surfactante Dodecil Sulfato de Sódio $\left(\operatorname{SDS}^{\circ}\right)$, os resultados aproximaram-se bastante daqueles encontrados para Tween 80 , sendo que após $144 \mathrm{~h}$ de exposição àquele agente e a 0,00001M, havia em média um total de apenas 5 adultos vivos. A $\mathrm{DL}_{50}$ alcançada para Tween 80 foi de $2,52 \times 10^{-4} \mathrm{M}$, ocupando posição intermediária em relação ao Triton X 100 e SDS. Não foram encontrados relatos na literatura que mencionam o Tween 80 como um agente larvicida. De forma geral, os resultados obtidos para os surfactantes sintéticos foram bastantes promissores, indicando, por exemplo a possibilidade de sua aplicação como aditivos aos compostos larvicidas tradicionalmente utilizados. Apesar do efeito significativo destes surfactantes na redução do número de larvas de $C$. quinquefasciatus, por se tratar de substâncias químicas sintéticas, sua aplicação exige estudos complementares a fim de se buscar alternativas de neutralização de eventuais efeitos nocivos sobre o meio ambiente ou ao homem, embora seus valores de $D L_{50}$ estejam na faixa de $10^{-4} \mathrm{M}$, ou seja, em níveis bastante reduzidos. Por outro lado, estudos relacionados aos seus potenciais efeitos sinergísticos, atuando em conjunto com inseticidas cujas formulações já não apresentam sua eficácia original, em virtude do desenvolvimento de resistência por parte de algumas espécies de invertebrados, podem apontar para novas aplicações daqueles sintéticos.

No que se refere aos surfactantes de origem biológica testados, observou-se que no caso do biossurfactante produzido por $P$. aeruginosa, somente após $96 \mathrm{~h}$ de exposição surgiram indivíduos adultos, indicando assim relativo atraso no surgimento dos mesmos. Outros autores, por sua vez, ao estudarem um metabólito secundário produzido por Pseudomonas fluorescens que apresentou efeito pupacida sobre espécimes de $C$. quinquefasciatus, $A$. aegypti e Anopheles stephensi, concluíram se tratar de um composto de natureza surfactante, um di-ramnolipídeo, confirmando assim a ação mosquitocida daquele composto de natureza biológica (PRABAKARAN, 2015). Para ambos os casos, não houve ação larvicida significativa, mas no caso do presente estudo, o atraso considerável no surgimento dos primeiros indivíduos adultos representa fato de grande relevância para aplicação destes compostos em situações específicas, ou seja, que exigem maior tempo em estágio larval para ação de outros princípios ativos. Isso significaria que o retardo na passagem dos estádios em $C$. quinquefasciatus apresentaria importantes implicações práticas, podendo inclusive indicar sua aplicação conjugada com formulações de inseticidas tradicionais, eventualmente potencializando a ação dos mesmos Não foram encontrados relatos na literatura que relacionam o efeito de surfactantes ramnolipídeos produzidos por $P$. aeruginosa, ou especificamente cepas de LBBMA 4951 sobre larvas, pupas ou insetos adultos de $C$. quinquefasciatus, sendo este, o primeiro relato relacionado.

Nos experimentos executados na presença de biossurfactantes produzidos por isolados de $B$. subtilis LBBMA 4914, os resultados indicaram a prevalência média de apenas $40 \%$ do total de larvas vivas ao final de 
48h de exposição. Tais resultados confirmam que a surfactina produzida por linhagens de B. subtilis apresenta potencial efeito larvicida e, comparativamente aos ramnolipídeos, ação mais efetiva e pronunciada. Relatos de ação larvicida empregando-se lipopeptídeos produzidos por isolados de $B$. subtilis podem ser confirmados na literatura, a exemplo dos trabalhos desenvolvidos por Das e Mukherjee (2006), da mesma forma que estudos desenvolvidos por Ghribi et al. (2012) que apontam para uma importante ação larvicida de biosurfactantes produzidos por B. subtilis SPB1 contra o lepidóptero Ephestia kuehniella. Outros autores também confirmaram a ação larvicida ou mosquitocida de surfactantes produzidos por diversos isolados do gênero Bacillus, a exemplo de Medeiros et al. (2005) e Armengol et al. (2006). Conforme ilustrado no Gráfico 1, ao final de $96 \mathrm{~h}$ de exposição à surfactina, existiam apenas $25 \%$ do total de larvas, pupas ou insetos adultos de $C$. quinquefasciatus vivos sob as condições testadas nos experimentos. Não se sabe exatamente qual o efeito desses biossurfactantes sobre a fisiologia, histologia ou metabolismo dos espécimes de $C$. quinquefasciatus, sendo proposta a realização de experimentos complementares baseados em cortes histológicos de regiões sensíveis a ação dos agentes exógenos.

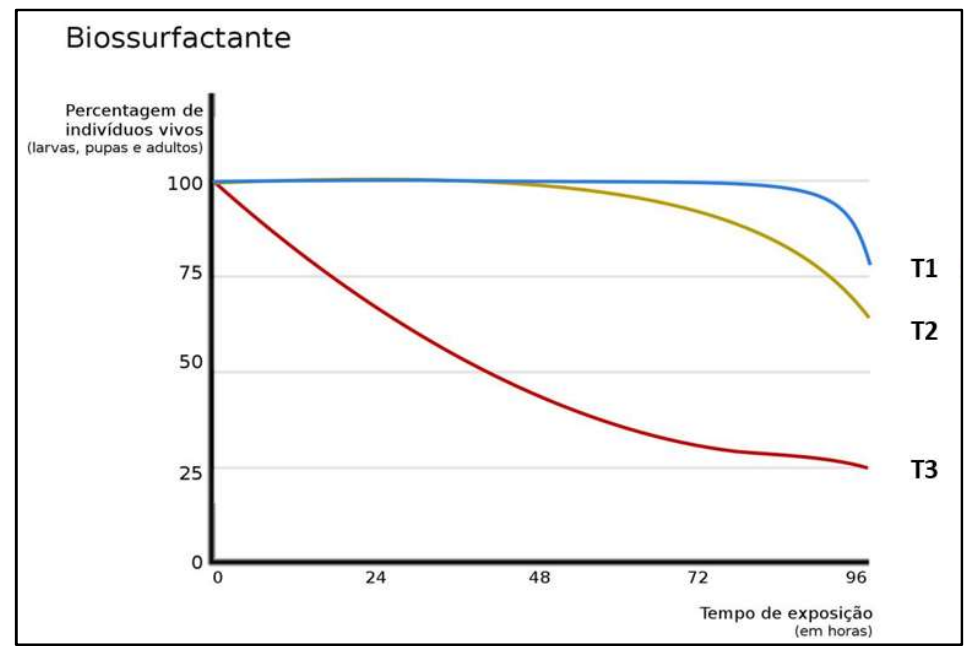

Figura 1: Grupo controle sem adição de biossurfactantes (T1). Em T2 são apresentados os resultados da adição de ramnolipídeos a 1,0 mg mL-1 sobre a percentagem de larvas, pupas e insetos adultos de $C$. quinquefasciatus ao longo de $96 \mathrm{hs}$. de exposição. Em T3 é apresentado o comportamento frente a surfactina nas mesmas condições experimentais.

Os resultados obtidos com o surfactante surfactina, produzida e pré-purificada a partir do cultivo de isolados de B. subtilis LBBMA 4914, foram bastante expressivos e promissores sendo possível vislumbrar a aplicação daquele agente biológico no controle da proliferação de mosquitos de $C$. quinquefasciatus. Além disso, ao final de $96 \mathrm{~h}$ de exposição àquele biosurfactante foi observada a existência de apenas $25 \%$, em média, do total de espécimes vivos, efeito de grande relevância e pertinência quando se especula sobre sua potencialidade de ação como agente bioinseticida. Geetha et al. (2011) observaram efeito mosquitocida promovido por surfactantes produzidos por isolados de B. amyloliquefaciens sobre Anopheles stephensi, C. quinquefaciatus e A. aegypti, embora seus resultados indiquem a necessidade de concentrações maiores de surfactantes para a obtenção de resultados similares aos obtidos em nosso trabalho. 
Estudos complementares fazem-se necessários a fim de se avaliar o comportamento de outras espécies de mosquitos da família Culicidae, a exemplo de Aedes aegypti, frente aos biossurfactantes aqui avaliados.

\section{CONCLUSÕES}

Conclui-se, portanto que há grande potencial de emprego de surfactantes sintéticos e biológicos no desenvolvimento de novos compostos destinados ao controle da proliferação de mosquitos ou atraso em seu desenvolvimento, podendo representar nova classe em potencial de insumos a serem utilizados no controle da proliferação de pragas ou vetores transmissores de doenças, como C. quinquefascitaus. A partir deste trabalho comprovou-se pronunciada ação do surfactante sintético Triton X 100 e do surfactante de origem biológica surfactina sobre larvas de $C$. quinquefaciatus. A surfactina produzida pode representar uma nova linha de bioinseticidas, mais efetivos e menos tóxicos, a serem aplicados no controle de infestação daqueles mosquitos. Os surfactantes sintéticos avaliados, por sua vez, podem exibir ação singergística quando associados aos inseticidas tradicionais, dados os efeitos observados. Abrem-se, portanto, novas perspectivas de aplicação desses tensoativos em substituição ou adição aos compostos químicos sintéticos rotineiramente utilizados, já ineficazes sob o ponto de vista de sua ação larvicida, diante da resistência desenvolvida por algumas espécies de Culex.

\section{REFERÊNCIAS}

ANDRADE, C. F. S.; NASCIMENTO, M. C.. Controle de culex quinquefasciatus (diptera: culicidae) pela eliminação de criadouros no bairro da graúna, Paraty - RJ. Revista de controle biológico, v.2, p.30-33, 2010.

ARIMA, K.; KAKINUMA A.; TAMURA G.. Surfactin, a crystalline peptide lipid surfactant produced by Bacillus subtilis: isolation, characterization and its inhibition of fibrin clot formation. Biochemical and Biophysical Research Communications, v.31, p.488-494, 1968.

BANAT, I. M.; SAMARAH N.; MURAD, M.; HORNE, R.; BANERJEE S.. Biosurfactant production and use in oil tank clean-up. World Journal of Microbiology and Biotechnology, v.7, p.80-88, 1991.

BARATA E. A. M. F.; CHIARAVALLOTI, N. F.; DIBO, M. R.; MACORIS, M. L. G.; BARBOSA, A. A. C.; NATAL, D.; BARATA, J. M. S.; ANDRIGUETTI, M. T. M.. Captura de culicídeos em área urbana: avaliação do método das caixas de repouso. Revista Saúde Pública, v.41, p.357-382, 2007.

CAMEOTRA, S. S.; MAKKAR, R. S.. Recent applications of biosurfactants as biological and immunological molecules. Curr. Opin. Microbiology, v.7, p.1-5, 2004.

CONSOLI R. A. G. B.; LOURENÇO-DE-OLIVEIRA, R.. Principais mosquitos de importância sanitária no Brasil. Rio de Janeiro: Fiocruz, 1994.

DEANE, L. M.. Observações sobre alguns hábitos dos adultos de Culex fatigans, o principal transmissor da filariose em
Belém, Pará. Revista do Serviço Especial de Saúde Pública, v.4, p.423-446, 1951.

FORATTINI, O. P.. Culicidologia Médica: identificação, biologia e epidemiologia. São Paulo: EDUSP, 2002.

GEETHA, I.; MANONMANI, A. M.; PRABAKARAN, G.. Bacillus amyloliquefaciens: A mosquitocidal bacterium from mangrove forests of Andaman \& Nicobar islands, India. Acta Tropica, v.120, n.3, p.155-159, 2011. DOI: http://doi.org/10.1016/j.actatropica.2011.07.006

GHRIBI, D.; ELLEUCH, M.; ABDELKEFI, L.; ELLOUZE, S. Evaluation of larvicidal potency of Bacillus subtilis SPB1 biosurfactant against Ephestia kuehniella (Lepidoptera: Pyralidae) larvae and influence of abiotic factors on its insecticidal activity. Journal of Stored Products Research, v.48, p.68-72, 2012.

GUGLIOTTI, M.. Inovação: Surfactante combate simultaneamente mosquitos e algas. São Paulo: Agência FAPESP, 2011.

LAPORTA, G. Z.; URBINATI, P. R.; NATAL, D.. Aspectos ecológicos da população de Culex quinquefasciatus Say (Diptera, Culicidae) em abrigos situados no Parque Ecológico do Tiête, São Paulo, SP. Revista Brasileira de Entomologia, v.51, p.125-127, 2006.

LIMA, T. M. S.. Produção de biossurfactantes visando ao tratamento de borra oleosa. Dissertação (Mestrado em 
Microbiologia Agrícola) - Universidade Federal de Viçosa, Viçosa, 2003.

MARGALIT, J.; BECKER, N.; BACK, C.; ZARITSKY, A.. Bacillus thuringiensis subsp. israelensis as a Biological Control Agent of Mosquitoes and Black Flies. In: FENG, T. Y.; CHAK, K. F.; SMITH, A. R.; MARGALIT, J.; CHILCOTT, C.; ROSE, R. I.. Bacillus thuringiensis. Biotechnology and environmental Benefits, Taiwan, v.1, p.521-556, 1995.

MEDEIROS, Z.; CESSE, E. P.; MENEZES, J. A.; LESSA, F.. Controle da filariose linfática no Brasil, 1951-2000. Epidemiologia e Serviços de Saúde, v.12, p.77-86, 2003.

NITSCHKE, M.; PASTORE, G. M.. Biossurfactantes: Propriedades e Aplicações. Química Nova, v.25, p.772-776, 2002.

TAIPE-LAGOS, C. B.; NATAL, D.. Abundância de culicídeos em área metropolitana preservada e suas implicações epidemiológicas. Revista de Saúde Pública, v.37, p.275-279, 2003.

WEI, Y. H.; CHU, I. M.. Enhancement of surfactin production in iron-enriched media by Bacillus subtilis ATCC 21332.

Enzyme and Microbial Technology, v.22, p.724-728, 1998.

WILKE, A. B. B.. Controle Genético de mosquitos Culex quinquefasciatus. Dissertação (Mestrado em Saúde Pública) - Universidade de Sao Paulo, São Paulo, 2008.

YOUSSEF, N.; SIMPSON, N.; DUNCAN, D.; MCINERNEY, K.; FOLMSBEE, M.; FINCHER, M.; KNAPP, R.. In Situ Biosurfactant Production by Bacillus Strains Injected into a Limestone Petroleum Reservoir. Applied and Environmental Microbiology, v.73, p.1239-1247, 2007. DOI: http://doi.org/10.1128/AEM.02264-06

ZEQUI, J. A. C.; LOPES, J.. Biological control of Culex (Culex) saltanensis Dyar, (Diptera, Culicidae) through Bacillus Controle de Aedes (Stegomyia) aegypti e Culex (Culex) quinquefasciatus Zequi et al. 134 thuringiensis israelensis in laboratory and field conditions. Revista Brasileira de Zoologia, v.24, p.164-168, 2007. DOI: http://dx.doi.org/10.1590/S0101-81752007000100020

YANOLA, J.; CHAMNANYAB, S.; LUMJUANC, N.; SOMBOONB, $P$.. Insecticides resistance in the Culex quinquefasciatus populations from northern Thailand and possible resistance mechanisms. Acta Tropica, v.149, p.232-238, 2015. DOI: http://doi.org/10.1016/j.actatropica.2015.06.011

ELUMALAI, D.; KALEENA, P. K.; MUJEERA, N. K..

Phytochemical screening and larvicidal activity of Tridax procumbens ( $\mathrm{L}$ ) against Anopheles stephensi (Liston), Aedes aegypti (L) and Culex quinquefasciatus (say). Int. J. Biosci. Res., v.2, p,1-14, 2013.

BAWIN, T.; SEYE, F.; BOUKRAA, S.; ZIMMER, J.-Y.; RAHARIMALALA, F. N.; NDIAYE, M.; COMPERE, P.; DELVIGNE, F.; FRANCIS, F.. Histopathological effects of Aspergillus clavatus (Ascomycota: Trichocomaceae) on larvae of the southern house mosquito, Culex quinquefasciatus (Diptera: Culicidae). Fungal Biology, v.120, n.4, p.489-499, 2016. DOI: http://doi.org/10.1016/j.funbio.2016.01.002

JIANG, J.; OBERDORSTER, G.; BISWAS, P.. Characterization of size, surface charge, and agglomeration state of nanoparticle dispersions for toxicological studies. J. Nano. Res., v.11, p.77-89, 2009.

DAS, K.; MUKHERJEE, A. K.. Assessment of mosquito larvicidal potency of cyclic lipopeptides produced by Bacillus subtilis strains. Acta Trop., v.97, p.168-173, 2006.

PRABAKARAN, G., HOTI, S.L., RAO, H. S. P., VIJJAPU, S. Dirhamnolipid is a mosquito pupicidal metabolite from Pseudomonas fluorescens (VCRC B426). Acta Tropica, v.148, p.24-31, 2015.

WHO. Homepage World Health Organization. 2016. 